\title{
A multicomponent frailty intervention for socioeconomically vulnerable older adults: a designed-delay study
}

\author{
II-Young Jang ${ }^{1,2}$ \\ Hee-Won Jung ${ }^{3}$ \\ Hyelim Park ${ }^{1,2}$ \\ Chang Ki Lee ${ }^{4}$ \\ Sang Soo $\mathrm{Yu}^{2}$ \\ Young Soo Lee' \\ Eunju Lee' \\ Robert J Glynn 5,6 \\ Dae Hyun Kim ${ }^{6,7}$
}

\begin{abstract}
'Department of Internal Medicine, Asan Medical Center, University of Ulsan College of Medicine, Seoul, Republic of Korea; ${ }^{2}$ PyeongChang Health Center \& County Hospital, Pyeongchang, Gangwon-Do, Republic of Korea; ${ }^{3} \mathrm{Graduate}$ School of Medical Science and Engineering, Korea Advanced Institute of Science and Technology (KAIST), Daejeon, Republic of Korea; ${ }^{4}$ Goldman Urology Clinic, Seoul, Republic of Korea; ${ }^{5}$ Division of Preventive Medicine, Department of Medicine, Brigham and Women's Hospital, Boston, MA, USA; ${ }^{6}$ Division of Pharmacoepidemiology and Pharmacoeconomics, Department of Medicine, Brigham and Women's Hospital, Boston, MA, USA; ' Division of Gerontology, Department of Medicine, Beth Israel Deaconess Medical Center, Boston, MA, USA
\end{abstract}

Correspondence: Eunju Lee Department of Internal Medicine, Asan Medical Center, University of Ulsan College of Medicine, 88, Olympic-ro 43-gil, Songpa-gu, Seoul 05505, Republic of Korea

$\mathrm{Tel}+82230103308$

Fax +82 24760824

Email eunjulee@amc.seoul.kr
This article was published in the following Dove Press journal:

Clinical Interventions in Aging

\begin{abstract}
Purpose: The primary aim of this study was to evaluate the effectiveness of a 6-month multicomponent intervention on physical function in socioeconomically vulnerable older adults in rural communities. As secondary aims, we evaluated the effectiveness of the intervention on frailty and other geriatric syndromes, sustained benefit at 12 months, and baseline characteristics associated with poor response.
\end{abstract}

Patients and methods: This designed-delay study was conducted in 187 adults (mean age: 77 years; $75 \%$ women) who were living alone or on a low income in three rural regions of Korea. A 24-week multicomponent program that consisted of group exercise, nutritional supplementation, depression management, deprescribing medications, and home hazard reduction was implemented with a planned 6-month interval from August 2015 through January 2017. The primary outcome was physical function, measured using the Short Physical Performance Battery (SPPB) score (range: 0-12; minimum clinically important difference $\geq 1$ ) at 6 months. Secondary outcomes included frailty phenotype, sarcopenia, Mini Nutritional AssessmentShort Form score (range: 0-14), Center for Epidemiologic Studies-Depression Scale score (range: 0-60), and falls.

Results: At 6 months, the SPPB score increased by 3.18 points (95\% CI: $2.89,3.48)$ from baseline. The program improved frailty (odds ratio: 0.06 ; 95\% CI: $0.02,0.16$ ), sarcopenia (odds ratio: 0.32; 95\% CI: 0.15, 0.68), Mini Nutritional Assessment-Short Form score by 1.67 points (95\% CI: $1.28,2.06)$, and Center for Epidemiologic Studies-Depression Scale score by -3.83 points (95\% CI: $-5.26,-2.39$ ), except for fall (rate ratio: 0.99; 95\% CI: 0.69, 1.43). These beneficial effects were sustained at 12 months. Body mass index $\geq 27 \mathrm{~kg} / \mathrm{m}^{2}$ and instrumental activities of daily living disability at baseline were associated with poor improvement in the SPPB score.

Conclusion: This 24-week multicomponent program had sustained beneficial effects up to 1 year on physical function, frailty, sarcopenia, depressive symptoms, and nutritional status in socioeconomically vulnerable older adults in rural communities. (ClinicalTrials.gov, NCT 02554994)

Keywords: clinical trial, exercise, frailty, geriatric assessment, malnutrition, public health practice

\section{Introduction}

The prevalence of frailty is disproportionately high in older adults who have limited social support or who live in rural areas. ${ }^{1,2}$ Due to limited access to health care facilities and resources in rural area, these older adults may be at greater risk for functional decline. A community-based public health intervention may be needed to reduce the risk of frailty and its consequences. 
Several randomized controlled trials have tested the effect of interventions targeting major risk factors for functional decline, such as physical inactivity, nutritional status, depression, or falls, in older adults. Some studies showed that exercise and nutritional supplementation improved physical function and frailty, ${ }^{3-6}$ whereas others found limited benefits. ${ }^{7-9}$ This heterogeneity is possibly due to differences in the intervention (exercise alone vs multicomponent, individual vs group, or center-based intervention vs home-based intervention), adherence, loss to follow-up, or target populations. In particular, the effectiveness and feasibility of these interventions in a resource-limited rural setting have not been well studied. Because designing a public health intervention with sustained benefit is a high priority for rural communities, it is useful to learn how long the benefit can be maintained once the intervention is completed. In addition, identifying the characteristics of people who are unlikely to improve from this intervention is important as they may need personalized case management, instead of a group intervention.
In this paper, we report the results of a designed-delay intervention study to evaluate the effectiveness of a 6-month multicomponent program that comprises group exercise training, nutritional supplementation, depression management, deprescribing medications, and home hazard reduction in older adults who live alone or are on low income in rural communities in Korea. The primary aim was to test the hypothesis that our multicomponent program would improve physical performance in 6 months. As secondary aims, we evaluated the effectiveness of the intervention on frailty and other geriatric syndromes, sustained benefit at 12 months, and baseline characteristics associated with poor response to our program.

\section{Patients and methods}

\section{Study design}

We conducted a designed-delay study wherein the intervention was rolled out sequentially in three geographic regions with a planned 6-month interval (see Figure 1).
Region A

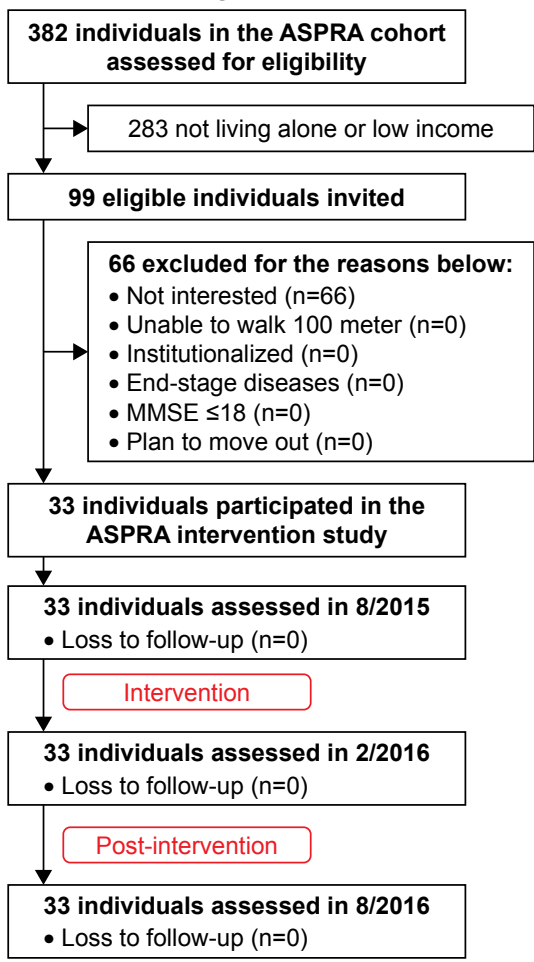

Region B

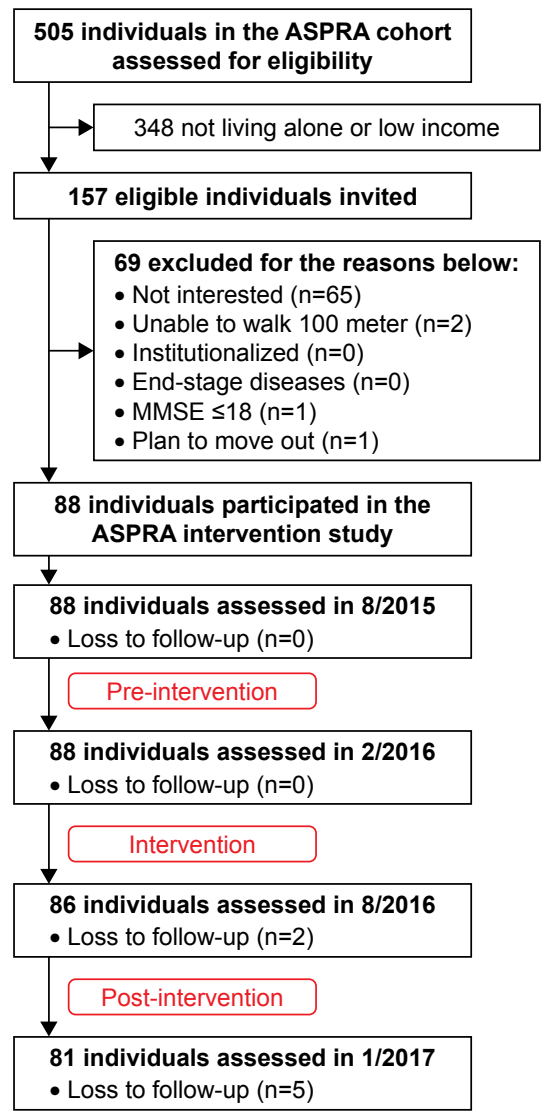

Region C

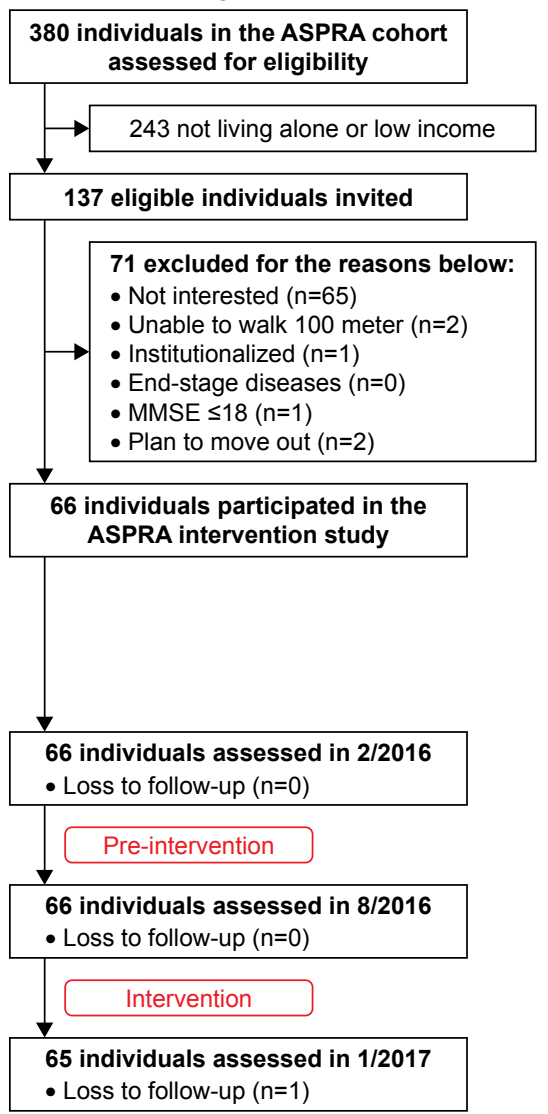

Figure I Study design and population of the Aging Study of Pyeongchang Rural Area, an intervention study. Notes: Participants for this study were selected from the Aging Study of Pyeongchang Rural Area, a population-based, prospective cohort study of aging in I,267 adults aged 65 years or older who live in three regions of Pyeongchang County, Gangwon Province, Korea. The 24-week intervention was delivered in one geographic region at a time. Enrolled individuals in region A participated in the multicomponent intervention program from August 2015 through January 2016; those in region B did so from February 2016 through July 2016; and those in region C participated from August 2016 through January 2017. All participants were assessed every 6 months for physical function. Abbreviation: ASPRA, Aging Study of Pyeongchang Rural Area. 
This pragmatic design was chosen after consulting regional and local public health workers and town representatives, who expressed concerns about the limited resources at the public health centers to conduct a randomized controlled trial and unfamiliarity of public health workers and town residents with random treatment assignment. A designeddelay study allowed efficient use of the existing infrastructure and limited resources by implementing the program in one region at a time, while residents in all three regions received the intervention after a prespecified delay during the study period. The effectiveness of an intervention can be evaluated by comparing the outcome with a historical (preintervention period) comparison group as well as a concurrent (non-intervention region) comparison group. Based on these results from the three regions, the public health center can decide whether or not to adopt this intervention for the entire county. The study protocol was approved by the Institutional Review Board of the Asan Medical Center (Research Protocol 2015-0706) and was registered with ClinicalTrials.gov (NCT 02554994).

\section{Study population}

This study was conducted between August 2015 and January 2017 in Pyeongchang County, a rural area located 180 km east of Seoul. The study population was recruited from the Aging Study of Pyeongchang Rural Area (ASPRA), a population-based, prospective cohort study of 1,267 adults aged $\geq 65$ years who lived in Pyeongchang County. ${ }^{10}$ The cohort included over $90 \%$ of older adults living in the study area. Individuals were included if they 1) were currently living in the three regions; 2) were aged 65 years or older; 3 ) were living alone or receiving medical aid services; and 4 ) signed informed consent. The exclusion criteria were as follows: 1) unable to walk $100 \mathrm{~m}$; 2) institutionalized in the past 6 months; 3) diagnosed with end-stage heart failure, end-stage renal disease, or metastatic cancer; 4) cognitively impaired (Mini-Mental State Examination score $\leq 18$ ); and 5) planning to move out of the study area in the next 6 months. All participants provided written informed consent.

\section{A multicomponent program}

A 24-week multicomponent program was implemented in one geographic region at a time: region A in August 2015-January 2016, region B in February 2016-July 2016, and region C in August 2016-January 2017. During the preintervention period, participants received usual care from the local public health centers. Usual care consists of ambulatory visit every month or as needed for medical management of chronic conditions from local public health centers without receiving any component of the intervention (described later). During the intervention period, they received group exercise training, nutritional supplements, depression management, deprescription of medications, and home hazard reduction (Table 1). Our intervention team comprised two part-time exercise trainers (equivalent to $15 \%$ of weekly working hours), three part-time physicians (5\% of weekly working hours), and two nurses or social workers (30\% of weekly working hours). A 60-minute group exercise session was held twice weekly by licensed exercise trainers at a local town hall. Each session focused on resistance, balance, and aerobic capacity for $\sim 20$ minutes each. Participants were given a written guide for exercises and were encouraged to exercise for 60 minutes daily on their own. In addition, all participants received two $125 \mathrm{~mL}$ nutritional supplement packs (ready to drink) per day. The nutritional supplement was provided free of charge by Maeil Dairies Co., Ltd (Seoul, Korea). Individuals with high depressive symptoms were evaluated monthly by a geriatrician or a psychiatrist and received pharmacologic management or supportive psychotherapy as indicated. Individuals taking $\geq 5$ prescription drugs were evaluated monthly by a geriatrician for the discontinuation or reduction of potentially inappropriate medications according to the 2012 Beers criteria. ${ }^{11}$ Visiting nurses and social workers made home visits to identify and fix anything that could lead to home hazards using the Home Fall Prevention Checklist by Centers for Disease Control and Prevention. ${ }^{12}$

\section{Outcome assessment}

Our primary outcome was change in physical function over 6 months, measured using the Short Physical Performance Battery (SPPB) that comprised repeated chair stands, standing balance, and gait speed. ${ }^{13}$ The minimal clinically important change in SPPB was a change of 1 point. ${ }^{14}$ Secondary outcomes were 1) frailty phenotype, ${ }^{15}$ 2) sarcopenia, ${ }^{16,17}$ 3) nutritional risk, ${ }^{18} 4$ ) depressive mood, ${ }^{19} 5$ ) number of falls, and 6) number of emergency room visits and hospitalizations (see Table S1). Assessments of SPPB, frailty, sarcopenia, nutritional risk, and depressive symptoms were performed every 6 months by a team of seven to eight trained nurses who were not aware of the participation status in the intervention study. Self-reported falls and health care utilization were assessed on a monthly basis during the intervention period to ensure the safety of participants; they were assessed every 3 months during the non-intervention period..$^{20}$

\section{Other measurements}

Trained nurses collected sociodemographic information and assessed multimorbidity, polypharmacy, activities of daily 
Table I Description of multicomponent intervention program

\begin{tabular}{|c|c|}
\hline Focus & Description of intervention \\
\hline Exercise & $\begin{array}{l}\text { - Intervention: } 60 \text {-minute group exercise session led by licensed exercise focusing on the following types. The intensity was } \\
\text { increased every month } \\
\text { I. Resistance ( } 20 \text { minutes): squat, plank, side plank, straight leg raises } \\
\text { 2. Balance ( } 20 \text { minutes): one-leg standing, shifting from side to side, heel-to-toe walk } \\
\text { 3. Aerobic/endurance ( } 20 \text { minutes): step up and down, quick pace, dancing } \\
\text { - Target: all participants } \\
\text { - Frequency: twice weekly }\end{array}$ \\
\hline Nutrition & $\begin{array}{l}\text { - Intervention: administration of } 125 \mathrm{~mL} \text { commercial liquid formula containing } 200 \mathrm{kcal} \text { of energy, } 24.5 \mathrm{~g} \text { carbohydrate, } \\
\text { I } 3 \mathrm{~g} \text { protein, } 5.63 \mathrm{~g} \text { essential amino acid, and } 7 \mathrm{~g} \text { fat } \\
\text { - Target: all participants } \\
\text { - Frequency: twice daily }\end{array}$ \\
\hline Depression & $\begin{array}{l}\text { - Intervention: evaluation by a geriatrician or a psychiatrist and administration of supportive psychotherapy or antidepressant } \\
\text { medication as clinically indicated } \\
\text { - Target: participants with the CES-D score }>20 \text { points at baseline } \\
\text { - Frequency: monthly }\end{array}$ \\
\hline Polypharmacy & $\begin{array}{l}\text { - Intervention: medication review by a geriatrician, and dose reduction or discontinuation of potentially inappropriate } \\
\text { medications according to the } 2012 \text { Beer's criteria } \\
\text { - Target: participants taking } \geq 5 \text { prescription medications at baseline } \\
\text { - Frequency: monthly }\end{array}$ \\
\hline Home hazards & $\begin{array}{l}\text { - Intervention: evaluation of home environment by a visiting nurse and a social worker using the Home Fall Prevention } \\
\text { Checklist by Centers for Disease Control and Prevention and modification of the environment to eliminate any identified } \\
\text { hazard } \\
\text { - Target: all participants with any identified home hazard at baseline } \\
\text { - Frequency: trimonthly }\end{array}$ \\
\hline
\end{tabular}

Abbreviation: CES-D, Center for Epidemiologic Studies Depression Scale.

living (ADL), and instrumental activities of daily living (IADL), as shown in Table S1. During the intervention period, we calculated the attendance to the group exercise sessions and the number of nutritional supplements consumed on a weekly basis; in addition, we assessed the attendance to monthly evaluation and management for depression and polypharmacy in those who were eligible for the respective intervention at the beginning of the intervention (baseline). The adherence rate was calculated by the number of sessions attended divided by the total number of sessions for each intervention component (or the number of nutritional supplement packs consumed divided by the total packs distributed) during the intervention period. A standardized questionnaire was used to assess severe adverse events requiring emergency room visit or hospitalization.

\section{Statistical analysis}

We estimated that at least 78 participants would be needed to detect a 1-point change in the SPPB score over 6 months, assuming the $\mathrm{SD}$ of the change score to be 2.1 points and $10 \%$ loss to follow-up. ${ }^{4,14}$ There were no planned interim analyses or stopping rules. Using two-sample $t$-test and chi-squared test, we examined how the characteristics of participants in the intervention study differed from those who declined to participate.
To assess the effectiveness of our multicomponent intervention program, we assessed the change in the mean SPPB score before and after the intervention for each geographic region. For continuous outcome measures, including SPPB, Center for Epidemiologic Studies Depression Scale (CES-D), and Mini Nutritional Assessment-Short Form scores, we used linear mixed-effects models that included a random intercept term for each participant and fixed-effect terms for time indicators (using the beginning of the intervention as baseline) and indicators for geographic regions. We used logistic mixed-effects models for frailty and sarcopenia with the same random- and fixed-effect terms and negative binomial mixed-effects model for the number of falls with $\log$ follow-up time as an offset. From these models, we estimated the program's immediate and sustained effects on the outcomes and its $95 \%$ CIs. As a post hoc secondary analysis, we included time indicators-by-subgroup interaction terms in the mixed-effects model to evaluate effect modification by baseline characteristics. In addition, we applied random forests $^{21}$ to identify baseline characteristics that predict good responders to the program. Good response was defined as an increase in the SPPB score $>1$ point or the total SPPB score $>10$ (out of 12 points) by the end of the intervention. Important baseline variables were selected by inspecting the mean decrease in accuracy due to exclusion of each variable 
in the "out-of-bag" sample which was not used to develop the decision rule. ${ }^{21} \mathrm{We}$ calculated the proportion of good vs poor responders according to these characteristics. All analyses were performed using $\mathrm{R}$ software version $3.3 .3{ }^{22}$ and a two-sided $P$-value $<0.05$ was considered statistically significant.

\section{Results}

\section{Study population}

Of the 1,267 ASPRA cohort participants, 393 (31.0\%) were eligible (Figure 1). After excluding 206 who declined the intervention $(n=196)$ or met the exclusion criteria $(n=10)$, we enrolled 187 individuals. Compared with the excluded individuals, the included individuals were older (mean age, 77.4 vs 76.0 years) and had a poorer health status, as evidenced by higher prevalence of multimorbidity $(61.0 \%$ vs $42.2 \%)$, polypharmacy ( $53.5 \%$ vs $22.8 \%$ ), ADL disability (24.6\% vs $16.0 \%$ ), sarcopenia (49.2\% vs $35.9 \%)$, undernutrition ( $78.1 \%$ vs $41.3 \%)$, and fall history ( $26.7 \%$ vs $14.1 \%)$, as shown in Table S2. Although the prevalence of geriatric conditions varied across the three regions, multimorbidity, polypharmacy, sarcopenia, and undernutrition were common (Table 2). The mean SPPB score ranged from 7.0 to 7.8 points; $25.8 \%-43.2 \%$ met the frailty phenotype criteria and $33.3 \%-46.5 \%$ had gait speed $<0.6 \mathrm{~m} / \mathrm{s}$.

\section{Adherence and follow-up}

On average, participants attended $83.7 \%$ of the group exercise sessions during the 24-week period and consumed $87.8 \%$ of nutrition packs provided during the intervention period (Table 3$)$. Those with greater depressive symptoms $(n=33)$ and polypharmacy $(n=100)$ attended $88 \%$ of evaluations which were conducted by a geriatrician or a psychiatrist. Home hazards were reduced in $91 \%$ of individuals who were identified as having a greater risk for home hazards at baseline. During the intervention period, six serious adverse events were reported: one distal radius fracture, one heart failure exacerbation, one coronary artery revascularization, one peptic ulcer, one metastatic lung cancer, and one fatal hemorrhagic stroke. Seven participants in region B (five refused due to health-related reasons and two moved out of the area) and one participant in region $\mathrm{C}$ (refused follow-up due to health-related reasons) were lost to follow-up.

\section{Effectiveness of a multicomponent program}

The multicomponent program had a sustained positive effect on physical function (Figure 2). Since we repeated outcome assessment 6 months after the conclusion of intervention in regions $\mathrm{A}$ and $\mathrm{B}$, we were able to assess the sustained effectiveness of our intervention at 12 months. The SPPB score

Table 2 Characteristics of the participants in Aging Study of Pyeongchang Rural Area, an intervention study

\begin{tabular}{|c|c|c|c|c|}
\hline Characteristics & $\begin{array}{l}\text { Total } \\
\text { population }\end{array}$ & $\begin{array}{l}\text { Region A intervention: } \\
\text { August 2015-January } 2016\end{array}$ & $\begin{array}{l}\text { Region B intervention: } \\
\text { February 2016-July } 2016\end{array}$ & $\begin{array}{l}\text { Region C intervention: } \\
\text { August 2016-January } 2017\end{array}$ \\
\hline Sample size, $\mathrm{n}$ & 187 & 33 & 88 & 66 \\
\hline Age, years, mean $\pm S D$ & $77.4 \pm 5.1$ & $78.1 \pm 4.9$ & $76.4 \pm 5.2$ & $78.3 \pm 4.9$ \\
\hline Female, n (\%) & |4| (75.4) & $29(87.9)$ & $59(67.0)$ & $53(80.3)$ \\
\hline Education, years, mean $\pm S D$ & $2.1 \pm 3.8$ & $2.5 \pm 3.8$ & $2.1 \pm 3.8$ & $1.8 \pm 3.9$ \\
\hline Low income, $\mathrm{n}(\%)$ & $49(26.2)$ & $8(24.2)$ & $31(35.2)$ & $10(15.2)$ \\
\hline Living alone, n (\%) & $15 \mid(80.7)$ & $26(78.8)$ & $62(70.5)$ & $63(95.5)$ \\
\hline Height, $\mathrm{cm}$, mean \pm SD & $150.5 \pm 8.1$ & $148.7 \pm 7.5$ & $151.6 \pm 8.2$ & $149.9 \pm 7.9$ \\
\hline Weight, kg, mean \pm SD & $55.8 \pm 10.2$ & $55.0 \pm 9.7$ & $55.4 \pm 9.8$ & $56.8 \pm I I . I$ \\
\hline $\mathrm{BMI}, \mathrm{kg} / \mathrm{m}^{2}$, mean $\pm \mathrm{SD}$ & $24.6 \pm 3.8$ & $24.7 \pm 3.4$ & $24.0 \pm 3.7$ & $23.8 \pm 4.1$ \\
\hline Multimorbidity, n (\%) & $114(61.0)$ & $22(66.7)$ & $51(58.0)$ & $4 I(62.1)$ \\
\hline Polypharmacy, n (\%) & $100(53.5)$ & $21(63.6)$ & $47(53.4)$ & $32(48.5)$ \\
\hline Gait speed $<0.6 \mathrm{~m} / \mathrm{s}, \mathrm{n}(\%)$ & $68(36.4)$ & $15(46.5)$ & $31(35.2)$ & $22(33.3)$ \\
\hline ADL disability, $\mathrm{n}(\%)$ & $46(24.6)$ & $7(2 \mid .2)$ & $32(36.4)$ & $7(10.6)$ \\
\hline IADL disability, n (\%) & $68(36.4)$ & $20(60.6)$ & $24(27.3)$ & $24(36.4)$ \\
\hline SPPB score, mean \pm SD & $7.4 \pm 2.2$ & $7.1 \pm 2.7$ & $7.8 \pm 2.1$ & $7.0 \pm 2.1$ \\
\hline Frailty, n (\%) & $66(35.3)$ & II (33.3) & $38(43.2)$ & $17(25.8)$ \\
\hline Sarcopenia, n (\%) & $92(49.2)$ & $16(48.5)$ & $43(48.9)$ & $33(50.0)$ \\
\hline MNA-SF score $\leq \mathrm{II}, \mathrm{n}(\%)$ & $146(78.1)$ & 31 (93.9) & $64(72.7)$ & $51(77.2)$ \\
\hline CES-D score $>20, n(\%)$ & $33(17.6)$ & $4(12.1)$ & $21(23.9)$ & $8(12.1)$ \\
\hline Fall in the past year, $\mathrm{n}(\%)$ & $50(26.7)$ & $5(15.2)$ & $27(30.7)$ & $18(27.3)$ \\
\hline
\end{tabular}

Abbreviations: ADL, activities of daily living; BMI, body mass index; CES-D, Center for Epidemiologic Studies Depression Scale; IADL, instrumental activities of daily living; MNA-SF, Mini Nutritional Assessment-Short Form; SPPB, Short Physical Performance Battery. 
Table 3 Adherence to multicomponent intervention program

\begin{tabular}{|c|c|c|c|c|c|c|}
\hline \multirow[t]{2}{*}{ Focus } & \multirow{2}{*}{$\begin{array}{l}\text { Definition of } \\
\text { adherence }\end{array}$} & \multirow{2}{*}{$\begin{array}{l}\text { Eligible } \\
\text { participants } \\
\text { n (\%) }\end{array}$} & \multicolumn{4}{|c|}{ Adherence (\%) } \\
\hline & & & $\begin{array}{l}\text { Total } \\
\text { population }\end{array}$ & $\begin{array}{l}\text { Region A } \\
\text { intervention: } \\
\text { August 2015- } \\
\text { January } 2016\end{array}$ & $\begin{array}{l}\text { Region B } \\
\text { intervention: } \\
\text { February 2016- } \\
\text { July } 2016\end{array}$ & $\begin{array}{l}\text { Region C } \\
\text { intervention: } \\
\text { August 2016- } \\
\text { January } 2017\end{array}$ \\
\hline Exercise & $\begin{array}{l}\text { Attendance to group } \\
\text { exercise sessions }\end{array}$ & $187(100)$ & 83.7 & 80.0 & 86.9 & 81.2 \\
\hline Nutrition & $\begin{array}{l}\text { Proportion of } \\
\text { supplements consumed }\end{array}$ & $187(100)$ & 87.8 & 90.7 & 79.1 & 97.8 \\
\hline Depression & $\begin{array}{l}\text { Attendance to } \\
\text { monthly visits }\end{array}$ & $33(17.6)$ & 88.4 & 87.5 & 88.9 & 87.5 \\
\hline Polypharmacy & $\begin{array}{l}\text { Attendance to } \\
\text { monthly visits }\end{array}$ & $100(53.5)$ & 88.5 & 88.1 & 91.5 & 84.4 \\
\hline Home hazards & $\begin{array}{l}\text { Correction of any } \\
\text { home hazards }\end{array}$ & 149 (79.7) & 91.3 & 85.7 & 91.3 & 93.8 \\
\hline
\end{tabular}

did not change before the intervention; however, it increased with the intervention and changed minimally after the intervention. Compared with the baseline score, the SPPB score increased by 3.18 points $(95 \% \mathrm{CI}: 2.89,3.48)$ at 6 months and by 3.24 points $(95 \%$ CI: $2.88,3.60)$ at 12 months (Table 4$)$. The program substantially reduced frailty (odds ratio: 0.08 at 6 months and 0.06 at 12 months) and sarcopenia (odds ratio: 0.21 at 6 months and 0.32 at 12 months). The Mini Nutritional Assessment-Short Form score improved by 1.67 points at 12 months (95\% CI: 1.28, 2.06); the CES-D score improved at 6 months ( -3.36 points; 95\% CI: $-4.55,-2.17)$ and at 12 months ( -3.83 points; 95\% CI: $-5.26,-2.39)$. However, the rate of falls did not significantly reduce (rate ratio: 0.99 at 6 months and 1.18 at 12 months).

\section{Post hoc analysis}

Female gender, multimorbidity, gait speed $<0.6 \mathrm{~m} / \mathrm{s}$, frailty, CES-D score $>20$ points, and ADL disability at baseline

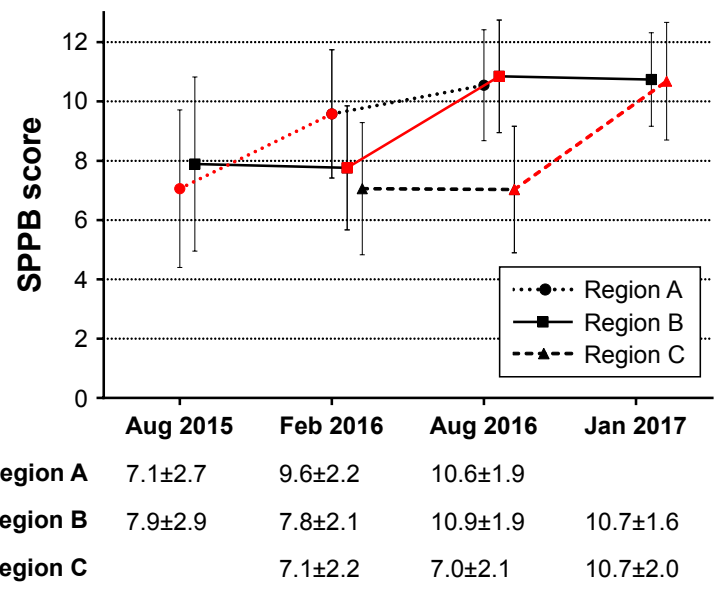

Figure 2 Physical function before and after multicomponent intervention program. Notes: The mean (node) and SD (vertical bar) of the SPPB score are presented for participants in the three geographic regions before and after the multicomponent intervention program. The intervention period is denoted in red. The table below the graph presents the mean $\pm S D$ for each region.

Abbreviation: SPPB, Short Physical Performance Battery. were associated with greater improvements in the SPPB score after the program $(P$-value for interaction $<0.05)$, as shown in Figure S1. When we examined the baseline variables for predicting $>1$-point SPPB improvement or $>10$ points at the end of the intervention, we found body mass index and IADL disability as the two most important baseline characteristics (Figure 3). Body mass index $<27 \mathrm{~kg} / \mathrm{m}^{2}$ and the absence of IADL disability at baseline were associated with good response to the intervention; the proportion of good responders decreased from $92 \%$ (84 of 91) to 53\% (10 of 19) when patients with body mass index $\geq 27 \mathrm{~kg} / \mathrm{m}^{2}$ and IADL disability were considered.

\section{Discussion}

This designed-delay intervention study found that our 24-week intervention program resulted in a clinically meaningful improvement in terms of physical function, frailty, sarcopenia, nutritional risk, and depression symptoms in older adults who were living alone or had low income in the rural community. Except for falls, the benefit was sustained for most outcomes at 6 months after the intervention. As such, a consistent level of improvement across the three different regions and three different periods provides strong evidence for the effectiveness of our intervention. In addition, the design and protocol of our study demonstrate that the effectiveness of a public health program can be evaluated in a resource-limited setting without randomization.

The results of our trial are consistent with the benefit of exercise alone or multicomponent interventions on objective measures of physical function reported in the literature (Table 5). Four studies showed a modest improvement in physical function ${ }^{3,7,8,23}$ (eg, SPPB score $0.6^{23}-1.0$ point $^{8}$ ) with exercise alone. Five studies of multicomponent interventions that included exercise, nutritional supplementation, and other 
Table 4 Effects of multicomponent program on physical function, frailty, and other geriatric conditions

\begin{tabular}{|c|c|c|c|c|c|}
\hline Outcome & $\begin{array}{l}\text { Time }^{\mathrm{a}} \\
\text { (months) }\end{array}$ & $\mathbf{N}_{\text {total }}^{\mathrm{b}}$ & $\mathbf{N}_{\text {drop-out }}{ }^{c}$ & $\begin{array}{l}\text { Summary } \\
\text { statistics }\end{array}$ & $\begin{array}{l}\text { Effect size } \\
(95 \% \mathrm{Cl})^{d}\end{array}$ \\
\hline \multirow[t]{3}{*}{$\mathrm{SPPB}$, mean $\pm \mathrm{SD}$} & 0 & 187 & 0 & $7.4 \pm 2.2$ & Reference \\
\hline & 6 & 184 & 3 & $10.6 \pm 2.0$ & MD: $3.18(2.89,3.48)$ \\
\hline & 12 & 114 & 5 & $10.7 \pm 1.7$ & MD: $3.24(2.88,3.60)$ \\
\hline \multirow[t]{3}{*}{ Frailty, n (\%) } & 0 & 187 & 0 & $66(35.3)$ & Reference \\
\hline & 6 & 184 & 3 & $12(6.5)$ & OR: $0.08(0.03,0.18)$ \\
\hline & 12 & 114 & 5 & $7(6.1)$ & OR: $0.06(0.02,0.16)$ \\
\hline \multirow[t]{3}{*}{ Sarcopenia, n (\%) } & 0 & 187 & 0 & $92(49.2)$ & Reference \\
\hline & 6 & 184 & 3 & $57(31.0)$ & OR: $0.2 I(0.1 I, 0.4 I)$ \\
\hline & 12 & 114 & 5 & $40(35.1)$ & OR: $0.32(0.15,0.68)$ \\
\hline \multirow[t]{3}{*}{ MNA-SF, mean $\pm S D$} & 0 & 187 & 0 & $10.7 \pm 2.2$ & Reference \\
\hline & 6 & 184 & 3 & $11.9 \pm 1.9$ & MD: I.20 (0.88, I.53) \\
\hline & 12 & 114 & 5 & $12.5 \pm 1.8$ & MD: I.67 (I.28, 2.06) \\
\hline \multirow[t]{3}{*}{ CES-D, mean $\pm S D$} & 0 & 187 & 0 & $10.8 \pm 9.6$ & Reference \\
\hline & 6 & 184 & 3 & $7.4 \pm 7.9$ & MD: $-3.36(-4.55,-2.17)$ \\
\hline & 12 & 114 & 5 & $7.3 \pm 9.0$ & MD: $-3.83(-5.26,-2.39)$ \\
\hline \multirow[t]{3}{*}{ No of falls per 100 person-days } & 0 & 187 & 0 & 0.47 & Reference \\
\hline & 6 & 186 & 1 & 0.35 & RR: $0.99(0.69,1.43)$ \\
\hline & 12 & 119 & 0 & 0.37 & RR: I.I8 (0.77, I.8I) \\
\hline
\end{tabular}

Notes: ${ }^{\mathrm{a}}$ The time between month 0 and month 6 represents the intervention period. ${ }^{\mathrm{b}}$ Only participants from region $\mathrm{A}$ and region $\mathrm{B}$ were assessed at month I2. ${ }^{\mathrm{C}}$ The rate of falls was calculated using data from all available person-time, even if some participants did not complete assessments at month 6 or month I2. ${ }^{\mathrm{d}}$ Effect sizes (MD, OR, or RR) were estimated from mixed-effects models that included a random intercept term for each participant and fixed-effect terms for time indicators (month 6 and month 12 ) and for geographic regions. The effect size comparing month 6 vs month 0 represents the immediate effect of the intervention. The effect size comparing month 12 vs month 0 represents the sustained effects of the intervention.

Abbreviations: CES-D, Center for Epidemiologic Studies Depression Scale; MD, mean difference; MNA-SF, Mini Nutritional Assessment-Short Form; OR, odds ratio; RR, rate ratio; SPPB, Short Physical Performance Battery.

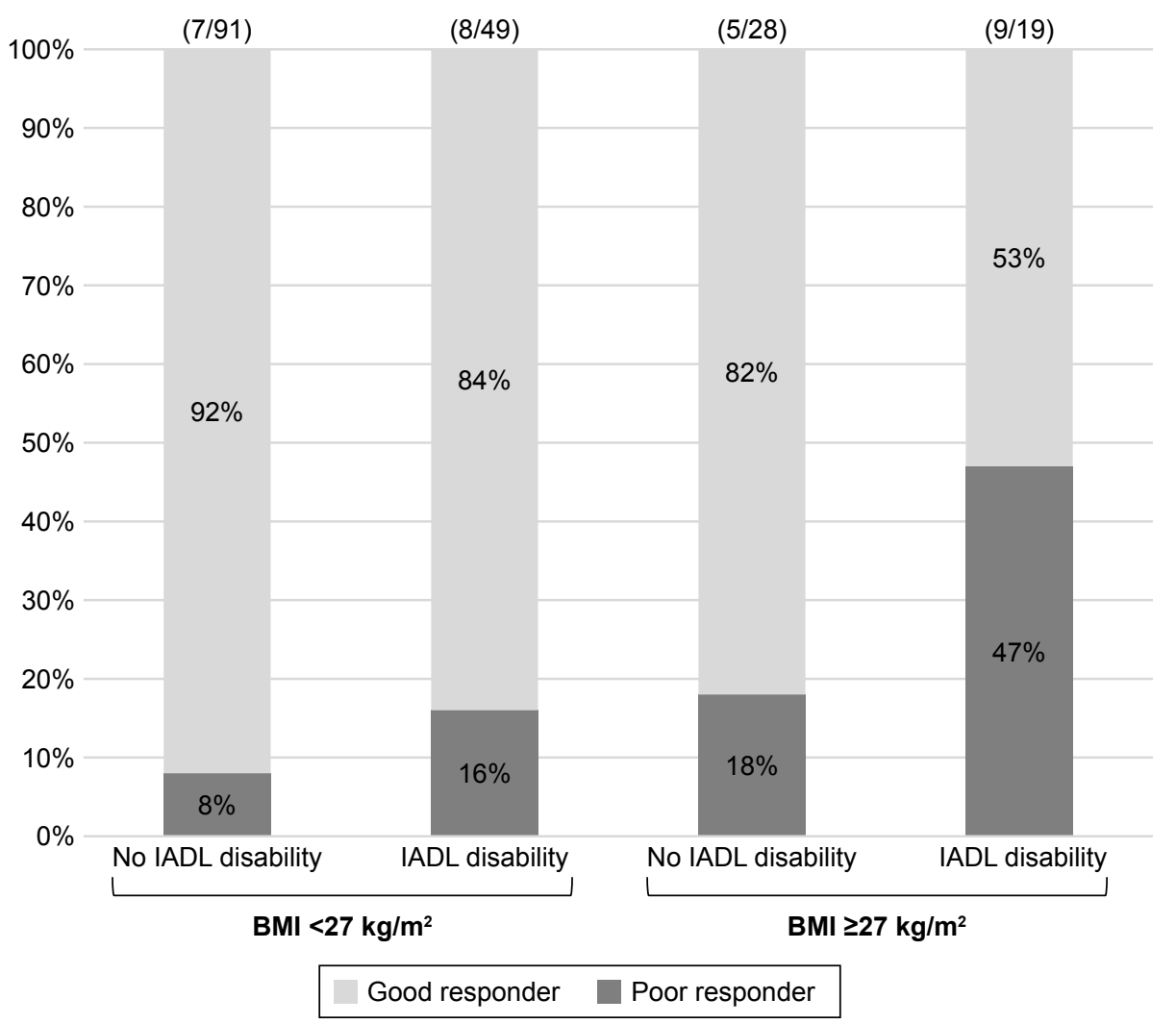

Figure 3 Prediction of response to multicomponent intervention program.

Notes: Good responders were defined as either those having an increase of $>$ I point in the SPPB score over the 24-week intervention period compared with the baseline score, or those with a total SPPB score increase of $>10$ points (range: 0-12 points; higher score indicates better physical function) at 6 months. Numbers on the top of the graph represent the number of poor responders/number of participants in each category.

Abbreviations: BMI, body mass index; IADL, instrumental activities of daily living; SPPB, Short Physical Performance Battery. 
Table 5 Randomized controlled trials of exercise intervention in community-dwelling older adults at risk for functional decline

\begin{tabular}{lll}
\hline Study & Population & Intervention \\
\hline Binder et al, $2002^{3}$ & Total N=II5 & Intervention: supervised group exercise \\
USA & Mean age: 83 years & - Three indoor exercises per week for \\
Women: $52 \%$ & 9 months \\
& - Gradually increasing intensity of flexibility, \\
& resistance, balance, and endurance \\
& Comparison: low-intensity exercise instruction \\
& - Two to three exercises per week at home \\
& for 9 months \\
& - Nine flexibility exercises
\end{tabular}

\begin{tabular}{|c|c|c|c|}
\hline Gill et al, $2004^{7}$ & Total $\mathrm{N}=188$ & Intervention: home-based physical therapy & - Physical function at 12 months \\
\hline \multirow[t]{5}{*}{ USA } & Mean age: 83 years & - Daily home exercise for 6 months, such & I. Timed rapid gait (seconds): +2.4 vs +6.0 \\
\hline & Women: $80 \%$ & as bed mobility, transfer, indoor gait, and & 2. Timed chair stand (seconds): -3.1 vs $-1.2^{\mathrm{a}}$ \\
\hline & & outdoor mobility & 3. Modified POMA (range: $0-12$ ): -0.5 vs -0.8 \\
\hline & & - Progressive, competency-based exercise & 4. Modified PPT (range: $0-12$ ): +1.3 vs $+0.2^{\mathrm{a}}$ \\
\hline & & including range of motion, balance, and & - Loss to follow-up: $6 \%$ vs $4 \%$ \\
\hline
\end{tabular}

muscle strengthening

Comparison: monthly home visit by a health

educator

\begin{tabular}{ll}
\hline LIFE-P, $2006^{8}$ & Total $\mathrm{N}=424$ \\
USA & Mean age: 77 years \\
& Women: $69 \%$
\end{tabular}

Intervention: physical activity program

- First 2 months (adoption): weekly centerbased sessions

- Next 4 months (transition): two centerbased sessions per week plus $\geq 3$ homebased sessions per week

- Final 6 months (maintenance): $\geq 3$ homebased sessions per week plus optional I-2 center-based sessions per week and monthly telephone follow-up

- Aerobics, strength, balance, and flexibility

Comparison: group education

\begin{tabular}{|c|c|c|c|}
\hline $\begin{array}{l}\text { McAuley et al, } 2013^{23} \\
\text { USA }\end{array}$ & $\begin{array}{l}\text { Total } \mathrm{N}=307 \\
\text { Mean age: } 71 \text { years } \\
\text { Women: } 77 \%\end{array}$ & $\begin{array}{l}\text { Intervention: DVD-delivered exercise program } \\
\text { - Three home-based programs per week for } \\
6 \text { months } \\
\text { - Two sets of II-I2 different exercises } \\
\text { focusing on flexibility, balance, and toning } \\
\text { Comparison: healthy aging DVD }\end{array}$ & $\begin{array}{l}\text { - Physical function } \\
\text { I. SPPB score (range: } 0-12 \text { ): }+0.6 \text { vs }-0 . I^{a} \\
\text { - Loss to follow-up: } 19 \% \text { vs } 11 \%\end{array}$ \\
\hline $\begin{array}{l}\text { Cameron et al, } 2013^{4} \\
\text { Australia }\end{array}$ & $\begin{array}{l}\text { Total } \mathrm{N}=24 \mathrm{I} \\
\text { Mean age: } 83 \text { years } \\
\text { Women: } 68 \%\end{array}$ & $\begin{array}{l}\text { Intervention: individualized, multidisciplinary } \\
\text { intervention targeting the CHS frailty domains } \\
\text { - Weakness, slowness, or low physical activity: } \\
\text { up to ten home-based physiotherapy sessions } \\
\text { and then three to five home exercise } \\
\text { program per week over the course of } \\
\text { I2 months (strength, balance, and endurance) } \\
\text { - Weight loss: home-delivered meals and } \\
\text { additional high-energy protein supplements } \\
\text { for I } 2 \text { months if BMI < I8.5 kg/m² or mid } \\
\text { upper arm circumference }<10 \text { th percentile } \\
\text { - Exhaustion: referred to a psychiatrist or } \\
\text { psychologist } \\
\text { Comparison: usual care } \\
\text { - General practitioner and medical specialist } \\
\text { consultations } \\
\text { commursing and allied health interventions by }\end{array}$ & $\begin{array}{l}\text { - Frailty and physical function at } 12 \text { months } \\
\text { I. CHS score (range: } 0-5 \text { ): }-0.80 \text { vs }-0.4 \text { I } \\
\text { 2. SPPB score (range: } 0-12 \text { ): }+0.52 \text { vs }-0.98^{a} \\
\text { - Loss to follow-up: I I } \% \text { vs } 10 \%\end{array}$ \\
\hline
\end{tabular}

- Physical function at 12 months

I. SPPB score (range: $0-12$ ): + I.0 vs +0.4

2. $400 \mathrm{~m}$ walk test $(\mathrm{m} / \mathrm{s}):-0.01$ vs $-0.03^{\mathrm{a}}$
- Loss to follow-up: $4 \%$ vs $9 \%$
Main findings

- Physical function at 9 months

I. Modified PPT (range: $0-36$ ): +3.4 vs $+0.8^{a}$

2. Peak $\mathrm{VO}_{2}(\mathrm{~mL} / \mathrm{kg} / \mathrm{min}):+2.0$ vs $-0.4^{\mathrm{a}}$

- Loss to follow-up: $30 \%$ vs $16 \%$ 
Table 5 (Continued)

\begin{tabular}{|c|c|c|c|}
\hline Study & Population & Intervention & Main findings \\
\hline $\begin{array}{l}\mathrm{Ng} \text { et al, } 2015^{5} \\
\text { Singapore }\end{array}$ & $\begin{array}{l}\text { Total } \mathrm{N}=246 \\
\text { Mean age: } 70 \text { years } \\
\text { Women: } 61 \%\end{array}$ & $\begin{array}{l}\text { Intervention: physical, nutritional, cognitive, } \\
\text { and combination intervention (four intervention } \\
\text { programs) } \\
\text { - Physical intervention: two group exercises } \\
\text { per week for I } 2 \text { weeks, followed by daily } \\
\text { individualized home-based exercise for } \\
12 \text { weeks } \\
\text { - Nutritional intervention: daily commercial } \\
\text { formula, iron, folate, and vitamin B6 and BI } 2 \\
\text { supplements for } 24 \text { weeks } \\
\text { - Cognitive training intervention: weekly } \\
\text { cognition-enhancing activity sessions for } \\
24 \text { weeks } \\
\text { - Combined intervention: all three } \\
\text { components } \\
\text { Comparison: usual health and aged care } \\
\text { services from government or private clinics and } \\
\text { hospitals } \\
\text { - Placebo supplement }\end{array}$ & $\begin{array}{l}\text { - Frailty at } 12 \text { months in physical intervention } \\
\text { group vs nutritional intervention group } \\
\text { vs cognitive training group vs combined } \\
\text { intervention group } \\
\text { I. CHS score (range: } 0-5 \text { ): }-0.83 \text { vs }-0.63 \\
\text { vs }-0.62 \text { vs }-0.92 \text { vs }-0.14^{\mathrm{a}} \\
\text { - Loss to follow-up: } 8 \% \text { vs } 10 \% \text { vs } 4 \% \text { vs } 6 \% \\
\text { vs } 8 \%\end{array}$ \\
\hline $\begin{array}{l}\text { Tarazona-Santabalbina } \\
\text { et al, } 2016^{6} \\
\text { Spain }\end{array}$ & $\begin{array}{l}\text { Total } \mathrm{N}=100 \\
\text { Mean age: } 80 \text { years } \\
\text { Women: } 54 \%\end{array}$ & $\begin{array}{l}\text { Intervention: a multicomponent exercise } \\
\text { program with nutritional support } \\
\text { - Five supervised-facility exercises per week } \\
\text { for } 24 \text { weeks; daily protein-calorie and } \\
\text { vitamin D supplementation } \\
\text { - Proprioception, aerobics, strength, and } \\
\text { stretching } \\
\text { Comparison: nutritional supplementation alone } \\
\text { - Protein-calorie and vitamin D supplements }\end{array}$ & $\begin{array}{l}\text { - Physical function and frailty at } 6 \text { months } \\
\text { I. SPPB score (range: } 0-12 \text { ): }+0.9 \text { vs }-1.5^{\mathrm{a}} \\
\text { 2. PPT score (range: } 0-36 \text { ): }+4.2 \text { vs }-2.2^{\mathrm{a}} \\
\text { 3. CHS score (range: } 0-5):-2.0 \text { vs } 0.0^{\mathrm{a}} \\
\text { - Loss to follow-up: } 20 \% \text { vs } 16 \%\end{array}$ \\
\hline $\begin{array}{l}\text { Serra-Prat et al, } 2017^{9} \\
\text { Spain }\end{array}$ & $\begin{array}{l}\text { Total } \mathrm{N}=172 \\
\text { Mean age: } 78 \text { years } \\
\text { Women: } 56 \%\end{array}$ & $\begin{array}{l}\text { Intervention: nutritional assessment and } \\
\text { physical activity program } \\
\text { - Four home-based exercises per week for } \\
\text { I } 2 \text { months } \\
\text { - Aerobics, resistance, and balance exercises } \\
\text { - Nutritional assessment and referral for } \\
\text { dietary recommendations } \\
\text { Comparison: usual care }\end{array}$ & $\begin{array}{l}\text { - Frailty at } \mathrm{I} 2 \text { months } \\
\text { I. Incident CHS frailty: }+4.9 \% \text { vs }+\mathrm{I} 5.3 \% \text { a } \\
\text { - Loss to follow-up: } 24 \% \text { vs } 22 \%\end{array}$ \\
\hline $\begin{array}{l}\text { Villareal et al, } 2017^{24} \\
\text { USA }\end{array}$ & $\begin{array}{l}\text { Total } \mathrm{N}=160 \\
\text { Mean age: } 70 \text { years } \\
\text { Women: } 64 \%\end{array}$ & $\begin{array}{l}\text { Intervention: a multicomponent exercise } \\
\text { program combined with dietary weight } \\
\text { management and calcium and vitamin D } \\
\text { supplementation (three intervention programs) } \\
\text { - Aerobic intervention: three individual } \\
\text { exercises per week on flexibility, aerobics, } \\
\text { and balance for } 26 \text { weeks } \\
\text { - Resistance intervention: three individual } \\
\text { exercises per week on flexibility, resistance, } \\
\text { and balance for } 26 \text { weeks } \\
\text { - Combined intervention: three individual } \\
\text { exercises per week for flexibility, } \\
\text { resistance, and balance, as well as aerobics } \\
\text { for } 26 \text { weeks } \\
\text { Comparison: education on a healthy diet } \\
\text { - Calcium and vitamin D supplementation }\end{array}$ & $\begin{array}{l}\text { Physical function at } 6 \text { months } \\
\text { I. PPT (range: } 0-36):+3.9 \text { vs }+3.9 \text { vs }+5.5 \\
\text { vs }+1.0^{\mathrm{a}} \\
\text { 2. Peak } \mathrm{VO}_{2}(\mathrm{~mL} / \mathrm{kg} / \mathrm{min}):+3.3 \text { vs }+\mathrm{I} .3 \text { vs }+3 . \mathrm{I} \\
\text { vs }+0 . \mathrm{I}^{\mathrm{a}} \\
\text { 3. One repetition maximal strength }(\mathrm{kg}):+5 \\
\text { vs }+49 \text { vs }+48 \text { vs }+2 \% \text { a } \\
\text { - Loss to follow-up: } 13 \% \text { vs } 13 \% \text { vs } 13 \% \text { vs } \\
\text { I0\% }\end{array}$ \\
\hline
\end{tabular}

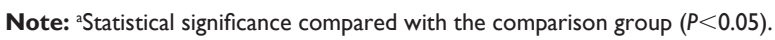

Abbreviations: BMI, body mass index; CHS, Cardiovascular Health Study; POMA, Performance Oriented Mobility Assessment; PPT, Physical Performance Test; SPPB, Short Physical Performance Battery. 
interventions (eg, mental health provider referral, ${ }^{4}$ cognitive training ${ }^{5}$ ) showed a moderate improvement in physical function $^{4,6,24}$ (eg, SPPB score $1.4^{4}-2.0$ points $^{6}$ ) and frailty phenotype. ${ }^{4-9}$ These are possibly due to lower adherence, difference in the intervention (targeting fewer components), nutritional supplementation only in selected individuals, and choice of young and less frail target populations in other studies. The Sarcopenia and Physical fRailty IN older people: multi-componenT Treatment strategies (SPRINTT) trial will confirm the long-term benefits of a multicomponent intervention in preventing mobility impairment in 1,500 older adults with frailty and sarcopenia in nine European countries. ${ }^{25}$

Our main objective was to evaluate the effectiveness of the intervention within the existing infrastructure of the regional public health center rather than establishing a clinical trial center. Therefore, our study design was influenced by the input from regional and local public health workers and town representatives. We enrolled residents who were living alone or on low income, because they had been identified by the local public health centers as high-priority individuals for various public health interventions. We previously found high burden of frailty and geriatric syndromes in these residents. ${ }^{10}$ Another advantage of targeting this population was that we were able to achieve efficient enrollment, high adherence, high retention, and more complete outcome assessment.

Although a randomized controlled trial is considered the gold standard to test the efficacy of an intervention, barriers to conducting a randomized controlled trial in rural areas have been well described. ${ }^{26-29}$ Previous research showed that older adults with low educational attainment or in rural communities might be unfamiliar with randomization. ${ }^{26-29}$ Public health officials are more interested in pragmatic implementation and evaluation of a program than scientific rigor; typically, the program evaluation is based on pre- vs post-intervention comparison. Such a design is subject to bias due to concurrent changes in clinical and public health practice that can result in an improvement in the outcome, unrelated to the intervention itself. Since most participants in our study received medical and preventive care through the local public health centers, we are certain that there were no major changes in usual care during the study period. Moreover, stable SPPB score in the pre-intervention period excludes the possibility of a practice effect or a spontaneous improvement. In summary, our study demonstrates that a designed-delay study can be an economically favorable alternative for testing the effectiveness of new therapies, programs, or policy changes in the routine care setting. ${ }^{30,31}$
This study has several limitations that deserve mention. First, our results derived from socioeconomically vulnerable older Koreans living in rural areas may not be generalizable to other populations. However, we believe that the physiologic effects of our program would be similar across populations. Second, the adherence to individual components of the intervention was less than perfect. We were unable to distinguish the effect of individual components. Our exercise and nutritional interventions were not individualized according to the nutritional status or muscle condition of each individual, mainly for practical reasons. Nonetheless, our intervention was highly effective in improving the physical function, as shown in other multicomponent interventions for geriatric syndromes (eg, falls ${ }^{32}$ and delirium ${ }^{33}$ ). Third, in a designeddelay study where the intervention was rolled out sequentially to different regions, any concurrent interventions outside our study may have affected the SPPB score. Given the nature of our intervention (eg, group exercise session, nutritional supplements, physician evaluation, and home safety evaluation) and the distance between the regions of intervention, we think that the chance of contamination across different regions is low. Fourth, we were unable to examine long-term clinical outcomes, such as mortality or institutionalization, because all participants received the intervention at some point. Fifth, in assessing falls and health care utilization, we interviewed participants on a monthly basis during the intervention period for safety monitoring and every 3 months during the non-intervention period. Higher surveillance frequency during the intervention period may have resulted in larger numbers of these outcomes at 6 months, which may have caused underestimation of the beneficial effect. Finally, further validation is needed to confirm whether obesity and IADL disability are predictors of poor response.

\section{Conclusion}

Our study shows that a 24-week multicomponent intervention program can effectively improve physical function, frailty, sarcopenia, depressive symptoms, and nutritional status in community-dwelling older populations. Most benefits seem to last at least 6 months after the intervention. A widespread adoption of our program as a public health intervention can potentially promote relatively healthy aging in older people.

\section{Acknowledgments}

We are indebted to the public health professionals and nurses of the Pyeongchang County Hospital, Public Health Center, and Community Health Posts for their administrative support 
and efforts in enrollment, retention, and measurements. We are also grateful to the representatives of each town who provided advice on the location, time, and duration of exercise intervention to maximize participant adherence.

The ASPRA, an intervention study, was funded by the Pyeongchang County Hospital, Pyeongchang County, Gangwon Province, Korea. This work was also supported, in part, by the Harvard Catalyst/The Harvard Clinical and Translational Science Center (National Center for Research Resources and the National Center for Advancing Translational Sciences, National Institutes of Health Award UL1 TR001102) as well as by financial contributions from the Harvard University and its affiliated academic health care centers. The content is solely the responsibility of the authors and does not necessarily represent the official views of the Harvard Catalyst, the Harvard University and its affiliated academic health care centers, or the National Institutes of Health.

Dr Dae Hyun Kim is supported by the Paul B Beeson Clinical Scientist Development Award in Aging (K08AG051187) from the National Institute on Aging, American Federation for Aging Research, The John A Hartford Foundation, and The Atlantic Philanthropies. He is also supported by the Boston Claude D Pepper Older Americans Independence Center/Pilot and Exploratory Studies Core Award (P30AG031679) and the Boston Roybal Center Pilot Award (P30AG048785).

The abstract of this paper was presented at the American Geriatrics Society 2018 Annual Scientific Meeting as a poster presentation with interim findings. The poster's abstract was published in "Abstract Supplement" in Journal of the American Geriatrics Society: Currently available at https:// meeting.americangeriatrics.org/sites/default/files/inlinefiles/2018-Journal of the American Geriatrics Society.pdf. Sponsor's role: Public health professionals and nurses of Pyeongchang County Hospital were involved in data collection, but they did not have any role in the study design, analysis or interpretation of data, writing of the paper, or the decision to submit the paper for publication. Paul Park and Maeil Dairies Co., Ltd did not have any role in the study design, collection, analysis or interpretation of data, writing of the paper, or decision to submit the paper for publication.

\section{Author contributions}

All authors participated in designing the study concept, performed statistical analysis, data analysis, and interpretation, and drafted the manuscript. The agreement is to be accountable for all aspects of the work in ensuring that the accuracy or integrity of any part of the work is appropriately investigated and resolved. All authors read and revised this manuscript. This manuscript is the final approval of version from all authors. All authors have reviewed and agreed to be responsible for the process, accuracy, and integrity of all parts of this manuscript.

\section{Disclosure}

Dr Dae Hyun Kim is a consultant to Alosa Health, a nonprofit educational organization with no relationship to any drug or device manufacturer. The other authors declare that there is no potential conflict of interests regarding the publication of this article.

\section{References}

1. Song X, Macknight C, Latta R, Mitnitski AB, Rockwood K. Frailty and survival of rural and urban seniors: results from the Canadian Study of Health and Aging. Aging Clin Exp Res. 2007;19(2):145-153.

2. Jang IY, Jung HW, Lee CK, et al. Rural and urban disparities in frailty and aging-related health conditions in Korea. $J$ Am Geriatr Soc. 2016;64(4):908-911.

3. Binder EF, Schechtman KB, Ehsani AA, et al. Effects of exercise training on frailty in community-dwelling older adults: results of a randomized, controlled trial. J Am Geriatr Soc. 2002;50(12):1921-1928.

4. Cameron ID, Fairhall N, Langron C, et al. A multifactorial interdisciplinary intervention reduces frailty in older people: randomized trial. BMC Med. 2013;11:65.

5. Ng TP, Feng L, Nyunt MS, et al. Nutritional, physical, cognitive, and combination interventions and frailty reversal among older adults: a randomized controlled trial. Am J Med. 2015;128(11):1225-1236.e1.

6. Tarazona-Santabalbina FJ, Gómez-Cabrera MC, Pérez-Ros P, et al. A multicomponent exercise intervention that reverses frailty and improves cognition, emotion, and social networking in the communitydwelling frail elderly: a randomized clinical trial. J Am Med Dir Assoc. 2016;17(5):426-433.

7. Gill TM, Baker DI, Gottschalk M, Peduzzi PN, Allore H, Van Ness PH. A prehabilitation program for the prevention of functional decline: effect on higher-level physical function. Arch Phys Med Rehabil. 2004;85(7):1043-1049.

8. LIFE Study Investigators; Pahor M, Blair SN, Espeland M, et al. Effects of a physical activity intervention on measures of physical performance: results of the lifestyle interventions and independence for Elders Pilot (LIFE-P) study. J Gerontol A Biol Sci Med Sci. 2006; 61(11):1157-1165.

9. Serra-Prat M, Sist X, Domenich R, et al. Effectiveness of an intervention to prevent frailty in pre-frail community-dwelling older people consulting in primary care: a randomised controlled trial. Age Ageing. 2017;46(3):401-407.

10. Jung HW, Jang IY, Lee YS, et al. Prevalence of frailty and agingrelated health conditions in older Koreans in rural communities: a cross-sectional analysis of the Aging Study of Pyeongchang Rural Area. J Korean Med Sci. 2016;31(3):345-352.

11. American Geriatrics Society 2012 Beers Criteria Update Expert Panel. American Geriatrics Society updated Beers Criteria for potentially inappropriate medication use in older adults. J Am Geriatr Soc. 2012;60(4): 616-631.

12. Centers for Disease Control and Prevention: Check for safety. a home fall prevention checklist for older adults. Available from: https://www. cdc.gov/steadi/pdf/check_for_safety_brochure-a.pdf(2005). Assessed 21 Jun 2015

13. Guralnik JM, Simonsick EM, Ferrucci L, et al. A short physical performance battery assessing lower extremity function: association with self-reported disability and prediction of mortality and nursing home admission. J Gerontol. 1994;49(2):M85-M94. 
14. Kwon S, Perera S, Pahor M, et al. What is a meaningful change in physical performance? Findings from a clinical trial in older adults (the LIFE-P study). J Nutr Health Aging. 2009;13(6):538-544.

15. Fried LP, Tangen CM, Walston J, et al. Frailty in older adults: evidence for a phenotype. J Gerontol A Biol Sci Med Sci. 2001;56(3): M146-M156.

16. Chen LK, Liu LK, Woo J, et al. Sarcopenia in Asia: consensus report of the Asian Working Group for Sarcopenia. J Am Med Dir Assoc. 2014;15(2):95-101.

17. Jang IY, Jung HW, Lee CK, Yu SS, Lee YS, Lee E. Comparisons of predictive values of sarcopenia with different muscle mass indices in Korean rural older adults: a longitudinal analysis of the Aging Study of PyeongChang Rural Area. Clin Interv Aging. 2018;13:91-99.

18. Kaiser MJ, Bauer JM, Ramsch C, et al. Validation of the Mini Nutritional Assessment short-form (MNA-SF): a practical tool for identification of nutritional status. J Nutr Health Aging. 2009;13(9):782-788.

19. Radloff LS. The CES-D scale: a self-report depression scale for research in general population. Appl Psychol Meas. 1977;1:385-401.

20. Yoo J, Kim S, Park W-C, Kim B-S, Choi H, Won CW. Discrepancy between quarterly recall and annual recall of falls: a survey of older adults. Ann Geriatr Med Res. 2017;21(4):174-181.

21. Breiman L. Random forests. Mach Learn. 2001;45(1):5-32.

22. R Development Core Team. R: A Language and Environment for Statistical Computing. Vienna, Austria: R Foundation for Statistical Computing (2017).

23. McAuley E, Wójcicki TR, Gothe NP, et al. Effects of a DVD-delivered exercise intervention on physical function in older adults. J Gerontol A Biol Sci Med Sci. 2013;68(9):1076-1082.

24. Villareal DT, Aguirre L, Gurney AB, et al. Aerobic or resistance exercise, or both, in dieting obese older adults. N Engl J Med. 2017;376(20): 1943-1955.
25. Landi F, Cesari M, Calvani R, et al. The "Sarcopenia and Physical fRailty IN older people: multi-componenT Treatment strategies" (SPRINTT) randomized controlled trial: design and methods. Aging Clin Exp Res. 2017;29(1):89-100.

26. Fougère B, Aubertin-Leheudre M, Vellas B, et al. Clinical research for older adults in rural areas: the MINDED study experience. Age (Dordr). 2016;38(2):30.

27. Cohen GI. Clinical research by community oncologists. CA Cancer JClin. 2003;53(2):73-81.

28. Maurer LH, Davis T, Hammond S, Smith E, West P, Doolittle M. Clinical trials in a rural population: professional education aspects. $J$ Cancer Educ. 2001;16(2):89-92.

29. Shavers VL, Lynch CF, Burmeister LF. Racial differences in factors that influence the willingness to participate in medical research studies. Ann Epidemiol. 2002;12(4):248-256.

30. Maclure M, Carleton B, Schneeweiss S. Designed delays versus rigorous pragmatic trials: lower carat gold standards can produce relevant drug evaluations. Med Care. 2007;45(10 Suppl 2):S44-S49.

31. D'Agostino RB Sr. The delayed-start study design. $N$ Engl J Med. 2009;361(13):1304-1306.

32. Tinetti ME, Baker DI, McAvay G, et al. A multifactorial intervention to reduce the risk of falling among elderly people living in the community. N Engl J Med. 1994;331(13):821-827.

33. Inouye SK, Bogardus ST Jr, Charpentier PA, et al. A multicomponent intervention to prevent delirium in hospitalized older patients. $N \mathrm{Engl}$ J Med. 1999;340(9):669-676. 


\section{Supplementary materials}

Table SI Details of outcome assessments and other measurements

\begin{tabular}{|c|c|c|c|}
\hline Outcomes & Measurements & Range & Reference \\
\hline \multicolumn{4}{|l|}{ Primary outcome } \\
\hline Short Physical Performance Battery & Repeated chair stands, standing balance, and gait speed & $0-12^{\mathrm{a}}$ & I, 2 \\
\hline \multicolumn{4}{|l|}{ Secondary outcomes } \\
\hline Frailty phenotype & According to the Cardiovascular Health Study criteria & $0-5$ & 3 \\
\hline & -Weight loss, exhaustion, low activity, slowness, and weakness & & \\
\hline Sarcopenia & $\begin{array}{l}\text { According to the consensus report of the Asian Working Group for Sarcopenia } \\
\text { - Low appendicular skeletal muscle mass measured using a bioimpedance } \\
\text { analysis (Inbody 620; InBody, Seoul, Korea) } \\
\text { - Decreased physical performance }\end{array}$ & Yes or no & 4,5 \\
\hline Nutritional risk & MNA-SF & $0-14^{b}$ & 6 \\
\hline Depressive symptoms & CES-D & $0-60^{c}$ & 7 \\
\hline Number of falls & Interview & Counts & 8 \\
\hline $\begin{array}{l}\text { Number of emergency room } \\
\text { visits and hospitalization }\end{array}$ & Interview & Counts & \\
\hline \multicolumn{4}{|l|}{ Other measurements } \\
\hline Sociodemographic & Interview & NA & \\
\hline Multimorbidity & $\begin{array}{l}\text { Having } \geq 5 \text { of the eleven physician-diagnosed conditions } \\
\text { - Angina, arthritis, asthma, cancer excluding minor skin cancer, chronic lung } \\
\text { disease, congestive heart failure, diabetes, heart attack, hypertension, kidney } \\
\text { disease, and stroke }\end{array}$ & Counts & 9 \\
\hline Polypharmacy & Defined as taking $\geq 5$ prescription medications & Counts & 9 \\
\hline Disability & $\begin{array}{l}\text { Requiring assistance in performing any of the ADLs and IADLs } \\
\text { - ADLs: bathing, continence, dressing, eating, toileting, transferring, and } \\
\text { washing face and hands } \\
\text { - IADLs: food preparation, household chores, going out for short distances, } \\
\text { grooming, handling finances, laundry, managing own medications, shopping, } \\
\text { transportation, and using telephone }\end{array}$ & Yes or no & 10 \\
\hline
\end{tabular}

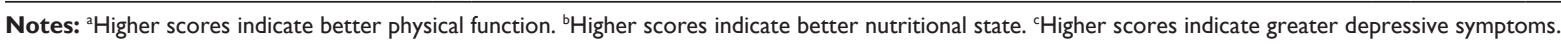
Abbreviations: ADL, activities of daily living; CES-D, Center for Epidemiologic Studies Depression Scale; IADL, instrumental activities of daily living; MNA-SF, Mini Nutritional Assessment-Short Form.

Table S2 Characteristics of individuals who were included or excluded from the Aging Study of Pyeongchang Rural Area, an intervention study

\begin{tabular}{|c|c|c|c|}
\hline \multirow[t]{2}{*}{ Characteristics } & \multicolumn{2}{|c|}{ Older adults living alone or with low income } & \multirow[t]{2}{*}{$P$-value } \\
\hline & Included & $\overline{\text { Excluded }}$ & \\
\hline Sample size, $\mathrm{n}$ & 187 & 206 & \\
\hline Age, years, mean $\pm S D$ & $77.4 \pm 5.1$ & $76.0 \pm 6.5$ & 0.025 \\
\hline Female, $\mathrm{n}(\%)$ & I4I (75.4) & $142(68.9)$ & 0.154 \\
\hline Education, years, mean $\pm S D$ & $2.1 \pm 3.8$ & $2.6 \pm 4.3$ & 0.186 \\
\hline Low income, n (\%) & $49(26.2)$ & $34(16.5)$ & 0.019 \\
\hline Living alone, $\mathrm{n}(\%)$ & $|5|(80.7)$ & $184(89.3)$ & 0.017 \\
\hline $\mathrm{BMI}, \mathrm{kg} / \mathrm{m}^{2}$, mean $\pm \mathrm{SD}$ & $24.6 \pm 3.8$ & $24.4 \pm 4.0$ & 0.600 \\
\hline Multimorbidity, n (\%) & $1 \mathrm{I} 4(6 \mid .0)$ & $87(42.2)$ & 0.001 \\
\hline Polypharmacy, n (\%) & $100(53.5)$ & $47(22.8)$ & 0.001 \\
\hline ADL disability, $\mathrm{n}(\%)$ & $46(24.6)$ & $33(16.0)$ & 0.034 \\
\hline IADL disability, n (\%) & $68(36.4)$ & $73(35.4)$ & 0.849 \\
\hline Gait speed $<0.6 \mathrm{~m} / \mathrm{s}, \mathrm{n}(\%)$ & $68(36.4)$ & $63(30.6)$ & 0.226 \\
\hline Frailty, n (\%) & $66(35.3)$ & $62(30.1)$ & 0.273 \\
\hline Sarcopenia, n (\%) & $92(49.2)$ & $74(35.9)$ & 0.008 \\
\hline MNA-SF score $\leq \mathrm{I}$ I, n (\%) & $146(78.1)$ & $85(4 \mid .3)$ & 0.001 \\
\hline CES-D score $>20, n(\%)$ & $33(17.6)$ & $31(15.0)$ & 0.489 \\
\hline Fall in the past year, $\mathrm{n}(\%)$ & $50(26.7)$ & $29(14.1)$ & 0.002 \\
\hline
\end{tabular}

Abbreviations: ADL, activities of daily living; BMI, body mass index; CES-D, Center for Epidemiologic Studies Depression Scale; IADL, instrumental activities of daily living; MNA-SF, Mini Nutritional Assessment-Short Form. 

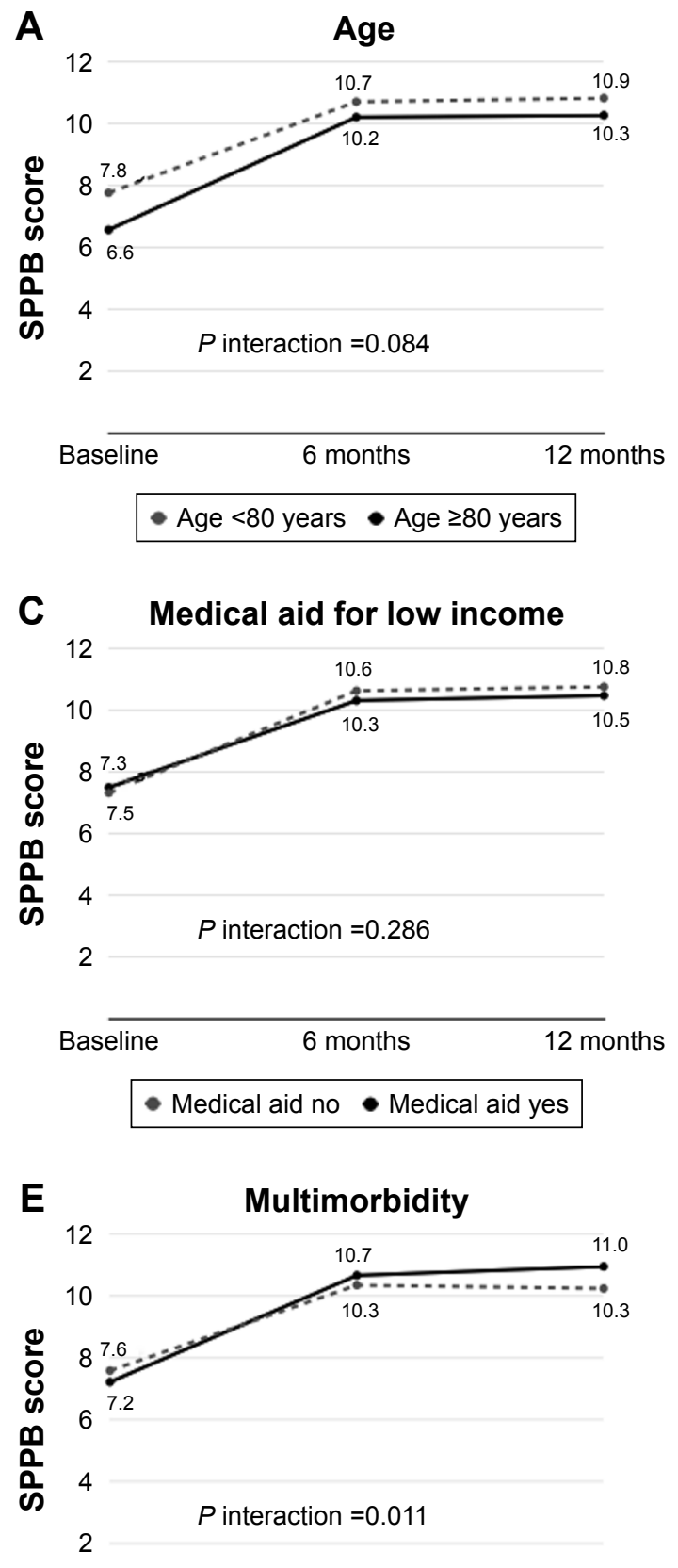

Baseline 6 months 12 months
\[ \text { Multimorbidity no } \bullet \text { Multimorbidity yes } \]

Figure SI (Continued)
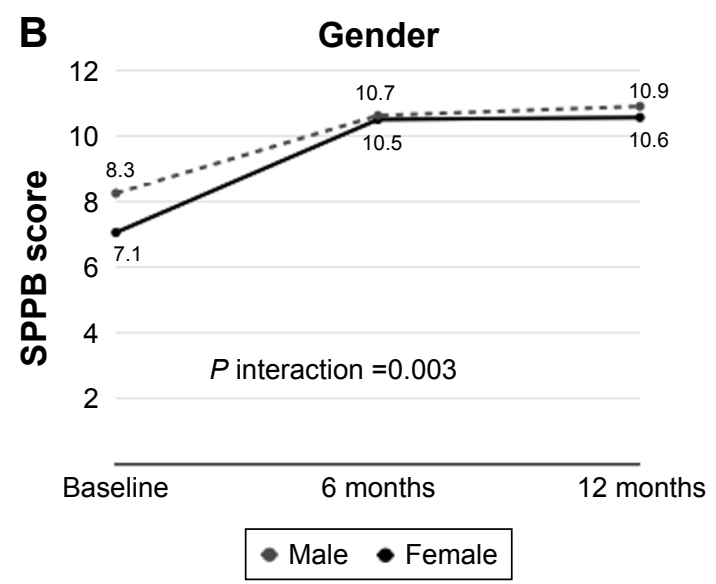

D
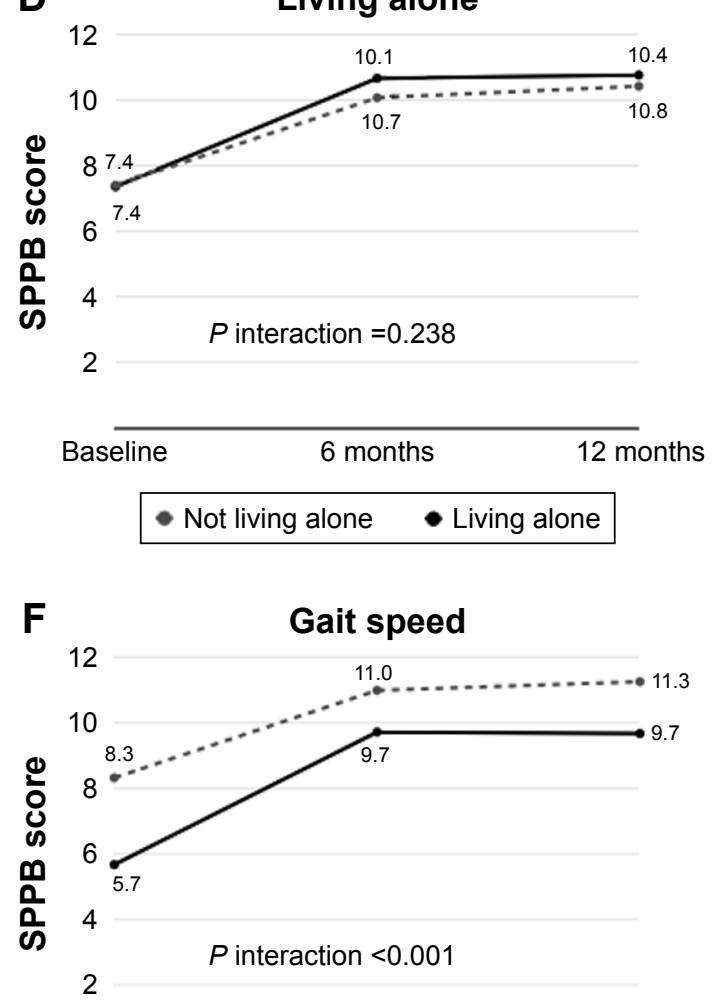

Baseline $\quad 6$ months 12 months
\[ \geq 0.6 \mathrm{~m} / \mathrm{s} \quad \bullet<0.6 \mathrm{~m} / \mathrm{s} \]



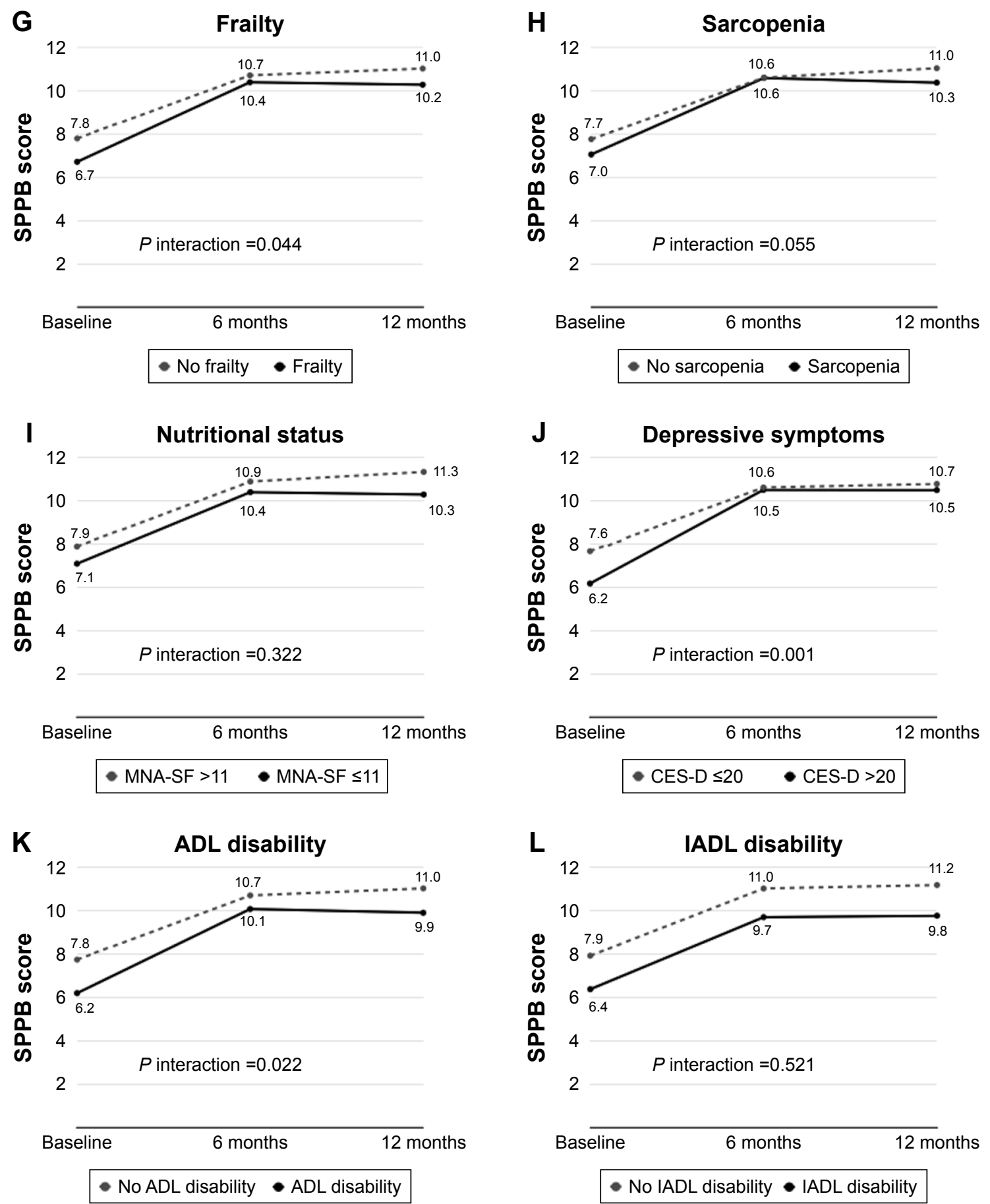

$\bullet$ No IADL disability $\bullet$ IADL disability

Figure SI Effect of multicomponent program by subgroups defined by baseline characteristics.

Note: Female gender, multimorbidity, gait speed $<0.6 \mathrm{~m} / \mathrm{s}$, frailty, CES-D score $>20$ points, and ADL disability at baseline were associated with greater improvements in the SPPB score after the program ( $P$-value for interaction $<0.05)$.

Abbreviations: ADL, activities of daily living; CES-D, Center for Epidemiologic Studies Depression Scale; IADL, instrumental activities of daily living; MNA-SF, Mini Nutritional Assessment-Short Form; SPPB, Short Physical Performance Battery. 


\section{References}

1. Guralnik J, Simonsick E, Ferrucci L, et al. Association with self-reported disability and prediction of mortality and nursing home admission. J Gerontol. 1994;49(2):M85-M94.

2. Kwon S, Perera S, Pahor M, et al. What is a meaningful change in physical performance? Findings from a clinical trial in older adults (the LIFE-P study). J Nutr Health Aging. 2009;13(6):538-544.

3. Fried LP, Tangen CM, Walston J, et al; Cardiovascular Health Study Collaborative Research Group. Frailty in older adults: evidence for a phenotype. J Gerontol A Biol Sci Med Sci. 2001;56(3):M146-M156.

4. Jang IY, Jung HW, Lee CK, Yu SS, Lee YS, Lee E. Comparisons of predictive values of sarcopenia with different muscle mass indices in Korean rural older adults: a longitudinal analysis of the Aging Study of PyeongChang Rural Area. Clin Interv Aging. 2018;13:91-99.

5. Chen LK, Liu LK, Woo J, et al. Sarcopenia in Asia: consensus report of the asian working group for sarcopenia. J Am Med Dir Assoc. 2014; 15(2):95-101.
6. Kaiser MJ, Bauer JM, Ramsch C, et al; MNA-International Group. Validation of the Mini Nutritional Assessment short-form (MNA-SF): a practical tool for identification of nutritional status. J Nutr Health Aging. 2009;13:782-788.

7. Radloff LS. The CES-D scale: a self-report depression scale for research in general population. Appl Psychol Meas. 1977;1:385-401.

8. Yoo J, Kim S, Park WC, Kim BS, Choi H, Won CW. Discrepancy between quarterly recall and annual recall of falls: a survey of older adults. Ann Geriatr Med Res. 2017;21(4):174-181.

9. Jung HW, Jang IY, Lee YS, et al. Prevalence of frailty and agingrelated health conditions in older Koreans in rural communities: a cross-sectional analysis of the Aging Study of Pyeongchang Rural Area. J Korean Med Sci. 2016;31(3):345-352.

10. Won CW, Yang KY, Rho YG, et al. The development of Korean Activities of Daily Living (K-ADL) and Korean Instrumental Activities of Daily Living (K-IADL) scale. J Korean Geriatr Soc. 2002;6: $107-120$.
Clinical Interventions in Aging

\section{Publish your work in this journal}

Clinical Interventions in Aging is an international, peer-reviewed journal focusing on evidence-based reports on the value or lack thereof of treatments intended to prevent or delay the onset of maladaptive correlates of aging in human beings. This journal is indexed on PubMed Central, MedLine,

\section{Dovepress}

CAS, Scopus and the Elsevier Bibliographic databases. The manuscript management system is completely online and includes a very quick and fair peer-review system, which is all easy to use. Visit http://www.dovepress. com/testimonials.php to read real quotes from published authors. 